IOSR Journal of Pharmacy

e-ISSN: 2250-3013, p-ISSN: 2319-4219, www.iosrphr.org

Volume 2 Issue 6 || || Nov-Dec. 2012 ||| PP.24-28

\title{
Antihypertensive efficacy of Lippia nodiflora - whole plant on uninephrectomized doca - salt hypertensive rats
}

\author{
Rekha Gadhvi ${ }^{1}$, Gaurav J Mishra*2, M. N. Reddy ${ }^{2}$ and Manish Nivserkar ${ }^{3}$ \\ ${ }^{1}$ Department of Biotechnology, Veer Narmad South Gujarat University, Surat, India. \\ ${ }^{2}$ Shree Bapalal Vaidhya Botanical Research Center, Department of Biosciences, \\ Veer Narmad South Gujarat University, Surat, India. \\ ${ }^{3}$ Pharmaceutical Education Research and Development Center, Ahmedabad, India.
}

\begin{abstract}
The plant Lippia nodiflora has been used traditionally as antihypertensive and has been proven scientifically to possess high antioxidant and hepato-protective activity. The present study has been designed to investigate the antihypertensive effect of methanolic extract of Lippia nodiflora on uninephrectomized DOCA-salt-induced hypertensive 'Wistar Rats'. During the experimental period, $1 \%$ sodium chloride solution was administered orally with drinking water for four weeks and DOCA-Salt (20 mg/kg body weight) was injected subcutaneously to elevate the systolic, diastolic and mean arterial blood pressure. The rats were then treated with the methanolic extract of Lippia nodiflora and a significant decrease in the systolic pressure was recorded. Biochemical assays including serum urea, serum creatinine, triglycerides, cholesterol, blood glucose and serum protein were also performed to assist the hypothesis. The study thus, concludes the antihypertensive activity of Lippia nodiflora in the DOCA-Salt hypertensive wister rats.
\end{abstract}

Keywords-Antihypertensive activity, Lippia nodiflora,Uninephrectomy, DOCA-Salt, Biochemical Assays

\section{INTRODUCTION}

Cardiovascular diseases account for 12 million deaths, annually worldwide and are known to be number one group of 'killer disease ${ }^{,[1]}$. Hypertension is the most common cardiovascular diseases and constituents a major factor for several cardiovascular pathologies including atherosclerosis, coronary artery disease, myocardial infract heart failure, renal insufficiency, stroke and dissecting aneurysm of aorta. Hypertension is one of the leading causes of disability, mortality and morbidity along the population and it is the most common chronic illness among the world faces ${ }^{[2]}$. An elevated arterial pressure is an important public health issue in developed countries. Although it is common, asymptomatic and readily detectable but it can often lead to lethal complication, if left untreated. Because of high incidence and morbidity, various drugs and regimes have been advocated for the control of hypertension. Many new drugs have also been introduced which may demonstrate better efficacy but possess side effects. Recently, attention has been focused towards herbal and mineral preparations which are traditionally used as potential therapeutic agents in the prevention and management of cardiovascular diseases ${ }^{[3,4]}$.

Hypertension, classically defined as systolic pressure $>165 \mathrm{mmHg}$ or diastolic blood pressure $>95 \mathrm{mmHg}$ or both, in adult. It is a non-infectious disease of global dimension in prevalence, incidence, complications, and deaths ${ }^{[5,6]}$. Early detection and commencement of chemotherapy are essential in preventing or delaying these complications and enhancing survival of the afflicted patients ${ }^{[7]}$. To treat hypertension coupled with associated complications, plants derived drugs have been used. They include Digitoxin from Digitalis purpurea (foxglove), Reserpine from Rauwolfia serpentina (snakeroot), Aspirin from Salix alba (willow bark), Tetramethylpyrazine, also known as Ligustrazine from Jatropha podagrica, and Tetrandrine from Stephenia tetradra ${ }^{[8,9]}$. These plant-derived pharmaceuticals have scientifically been proven to elicit antihypertensive activity via multiple mechanisms. These mechanisms are elicited to counteract the effect of hypertension and associated risk factors such as hypercholesterolemia, hypertriglyceridaemia, and oxidative stress on blood vessel wall ${ }^{[10]}$. The stated chemotherapeutic drugs include direct vasodilation of the blood vessel, blocking of calcium channels, inhibition of $\alpha$-adrenoreceptor response, induction of negative ionotropic response of smooth muscle, inhibition of platelet aggregation, reduction of vascular resistance, and improvement of pulmonary oxygen utilization ${ }^{[11,12,13]}$. Enhanced activity of nitric oxide and improved handling of intracellular calcium has also been found to play a critical role in the reduction of vascular resistance and blood pressure that are elevated in hypertensive rats and humans ${ }^{[14,15]}$. 
In the last 2 decades, plants have remained historically important as sources of novel compounds with potentials of being channelled into drug pipelines for the development of safe, efficacious, and cost-effective antihypertensive drugs. In sub-Saharan Africa, the initial ethno pharmacological surveys have identified over 100 species of plants with antihypertensive activity in animals and humans ${ }^{[16,17]}$. Among these plants Lippia nodiflora (Verbenaceae) is also one, which is commonly called as Bhujokra in Hindi, Ratoliya in Gujarati and Jalpippali in Sanskrit. It is a creeping, prostate, much branched perennial herb with branches spreading profusely and rooting at the nodes. It is found throughout warmer parts of India ascending up to $900 \mathrm{mt}$ in the hills. It is common in wet places, along irrigation channels, canal edges and river banks. Several workers have reported many pharmacological properties including antispasmodic hair afflictions, anti inflammatory, analgesic and antipyretic, antibacterial anti Helicobacter pylori activity, antinociceptive and antifungal activity of the plant ${ }^{[18]}$. Antihypertensive activity of $L$. nodiflora has been not reported till now, and this made the authors to investigate the potential antihypertensive property of the plant on DOCA-Salt hypertensive rats.

\section{MATERIALS AND METHODS}

Collection of Plant Sample: Whole plant, Lippia nodiflora was collected from Botanical Garden at Shri Bapalal Vaidya Botanical Research Centre of Biosciences, Department of Biosciences, Veer Narmad South Gujarat University, Surat, Gujarat, India. The plant was authenticated and voucher specimen of the plant was deposited in the herbarium of the University. The whole plant was washed under running tap water followed by distilled water and dried at $40^{\circ} \mathrm{C}$ in the oven for 3 days. The dried plant was then pulverized into fine powder that passed through a 30-mesh sieve and stored for the future use ${ }^{[19]}$.

Preparation of Extract: The ground plant material was subsequently extracted with methanol using Soxhlet apparatus. The resulting crude methanolic extract was filtered by passing through a Whatmann No. 3 filter paper followed by concentrating in vacuum at $40^{\circ} \mathrm{C}$ using a rotary evaporator and freeze drying. The freeze dried sample was suspended in $0.2 \%$ agar solution and mixed thoroughly ${ }^{[20,21]}$.

Experimental Protocol: Albino Wister rats (Young animal wt 150-200 gm) were obtained from the Animal House, Department of Pharmacology and Toxicology, B.V.Patel Perd Centre, at Ahmadabad, India. Animals were housed ( 3 rats/cage) in polypropylene cages lined with husk, renewed every $24 \mathrm{hr}$ under a 14:10 hr of light/dark regime and had free access to tap water and food. The rats were fed on a standard pellet diet. The experimental protocol was approved by the Institutional Animal House Ethics Committee, constituted by the Ministry of Social Justice and Empowerment, Government of India, prior to the initiation of the experiment.

Induction of Hypertension (Uninephrectomy): Left uninephrectomy was performed on all the rats by anaesthetizing with intramuscular injection of Ketamine $(20 \mathrm{mg} / \mathrm{kg}$.). The kidney was visualized by a left lateral abdominal incision, and the left renal artery and ureter were ligated by silk thread, followed by the removal of left kidney. The muscle and skin layer (incision site) were sutured with highly sterile suture needles. After uninephrectomy, rats were allowed to drink tap water ad libitum, with no further treatment. All uninephrectomized animals were given $1 \% \mathrm{NaCl}$ in the drinking water with weekly twice subcutaneous injection of DOCA-Salt ( $20 \mathrm{mg} / \mathrm{kg}$ body wt in olive oil) for four consecutive weeks (DOCA-salt hypertensive rat). The rats were then, randomly divided into four groups each comprising of four rats including 2 males and 2 females (Table 1).

Experimental work out on DOCA-Salt Hypertensive rats: the four groups of the hypertensive rats were divided according to the table 1 and categorized into normal control, disease control, positive control and test group. The animals in the group 1 were not given any surgery or treatment at all, while the group 2 animals were undergone for only surgery and no treatment was done. The animals in group 3 were undergone for surgery and treated with standard drug, ramiprill at $1 \mathrm{mg} / \mathrm{kg}$ of the total body weight. The animals in the group 4 were undergone for surgery and treated with the plant extract at $500 \mathrm{mg} / \mathrm{kg}$ of the total body weight (Table 1).

The test animals were treated with the stated dose of plant extract at every $24 \mathrm{hr}$ interval, consecutively for 14 days. Systolic and diastolic blood pressures were recorded every week during the entire period of the study by tail cuff method (IITC, Non-Invasive Blood Pressure Instrument) ${ }^{[22]}$. All the recordings and data analyses were done using computerized data acquisition system and software. At the end of treatment, all the rats were anesthetized with intramuscular injection of Ketamine and sacrificed in $\mathrm{CO}_{2}$ incubator for biochemical assays.

Biochemical Assays: At the end of the treatment, after a $12 \mathrm{hr}$ of fast but via access to deionised water, the animals in groups' I-IV were sacrificed. Blood samples were collected from each of the animal by retina puncture into plain sterile tubes. Each blood sample was allowed to clot and tubes were subsequently centrifuged at $2000 \mathrm{rpm}$ for $5 \mathrm{~min}$ to obtain sera which was transferred into new tubes and kept at $-20^{\circ} \mathrm{C}$ until used for bioassays.

From each of the sample sera, serum urea, serum creatinine, triglycerides, cholesterol, glucose and protein, were measured by biochemical analyser, Erba 360 - fully automated clinical chemistry analyser ${ }^{[22,23]}$. 


\section{STATISTICAL ANALYSIS}

The statistical approaches for the data generated were evaluated by the SPSS-15 statistical software. Analysis includes the expression of data in deviation of mean values (SD). Differences in mean values of biochemical parameters investigated between the treatment groups, the control and the involving treatment period were analyzed using chi-square test. The $P$ value was considered to be 0.05 and the outcomes with $P$ value below 0.05 were considered to be significant.

\section{RESULTS AND DISCUSSION}

Kidney plays a central role in the regulation of the balance of the body salt and water, and then disordered regulation of renal functions is responsible for the altered balance of salt and water in pathophysiological states including some experimental models of hypertension ${ }^{[24]}$. The systolic and diastolic blood pressure were considerably $(\mathrm{P}<0.05)$ increased in DOCA-salt hypertensive rats compared to normal control. Oral administration of plant extract $500 \mathrm{mg} / \mathrm{kg}$ total body weight) for a period of two weeks considerably $(\mathrm{P}<0.05)$ decreased systolic pressure in DOCA-salt treated rats (about $21 \%)$, where as in positive control with remiprill the reduction was about $13 \%$ (Table 2; Fig 1). This considerable reduction in the blood pressure by Lippia nodiflora might be due to the ACE inhibition property of the plant, mimicking the structure of its substrate, like Ramiprill which is an ACE inhibitor. ACE inhibitors directly block the formation of Angiotensin-II, and increasing bradykinin level simultaneously. The net results are reduced vasoconstriction, reduced sodium and water retention and increased vasodilation (through bradykinin). The increase in bradykinin level is due to less inactivation done by ACE enzyme. Lippia nodiflora has also been reported for diuretic activity $^{[18]}$.

The biochemical parameters including serum urea, creatinine, triglycerides, cholesterol, glucose and protein did not show any significant variation (data not shown) as reported by Prahalathan for morin in DOCA salt induced hypertension ${ }^{[23]}$, where a significant variation in serum creatinine and urea is reported. However, further studies are needed to know the exact mechanism of antihypertensive action of plant.

An increased concentration of aldosterone leads to increased re-absorption of sodium ions and water from epithelial cells in the distal nephron of kidney, thereby influencing the blood pressure levels ${ }^{[25]}$. In addition, increased aldosterone concentrations may activate oxidative stress in the DOCA-salt model ${ }^{[26]}$. In agreement with previous reports ${ }^{[27]}$, we also observed that systolic and diastolic blood pressures were considerably increased in DOCA-salt hypertensive rats, which might be due to increased oxidative stress and decreasing the bioavailability of nitric oxide. Daily oral administration of plant extract resulted in a remarkable reduction in systolic blood pressure which is due to antihypertensive property of this plant.

\section{ACKNOWLEDGEMENT}

The authors are grateful to B. V. Patel PERD Center, Ahmedabad, Gujarat, India for providing the experimental animals and laboratory facilities.

TABLES AND FIGURES

Table 1: Group distribution and treatment form.

\begin{tabular}{|lllll|} 
Group 1 & $\begin{array}{l}\text { Normal } \\
\text { control }\end{array}$ & Without surgery and treatment & \\
Group 2 & $\begin{array}{l}\text { Disease } \\
\text { control }\end{array}$ & $\begin{array}{l}\text { Uninephroctimized rat without any } \\
\text { treatment }\end{array}$ & \\
\hline Group 3 & $\begin{array}{l}\text { Positive } \\
\text { control }\end{array}$ & $\begin{array}{l}\text { Uninephroctimized rat treated with } \\
\text { standard positive control }\end{array}$ & $\begin{array}{l}\text { Ramiprill, } 1 \mathrm{mg} / \mathrm{kg} \quad \text { body } \\
\text { weight }\end{array}$ \\
\hline Group 4 & Test group & $\begin{array}{l}\text { Uninephroctimized rat treated with } \\
\text { plant extract }\end{array}$ & $\begin{array}{l}\text { Methanolic extract, 500mg/kg } \\
\text { body weight }\end{array}$ \\
\hline
\end{tabular}

Table 2: Effect of plant extract on DOCA-Salt hypertensive rats.

\begin{tabular}{|llll|}
\hline Group & 0 day $(\mathrm{mmHg})$ & $7^{\text {th }}$ day $(\mathrm{mmHg})$ & $1^{\text {th }}$ day $(\mathrm{mmHg})$ \\
\hline Normal control & $129.96 \pm 1.65$ & $129.96 \pm 1.65$ & $129.73 \pm 3.03$ \\
\hline Disease control & $169.57 \pm 13.55$ & $163.87 \pm 2.39$ & $163.87 \pm 4.21$ \\
\hline Positive control & $177.17 \pm 6.65$ & $146.3 \pm 12.69$ & $144.15 \pm 3.97$ \\
\hline Test group & $174.42 \pm 7.03$ & $136.73 \pm 4.84$ & $134.08 \pm 3.08$ \\
\hline
\end{tabular}




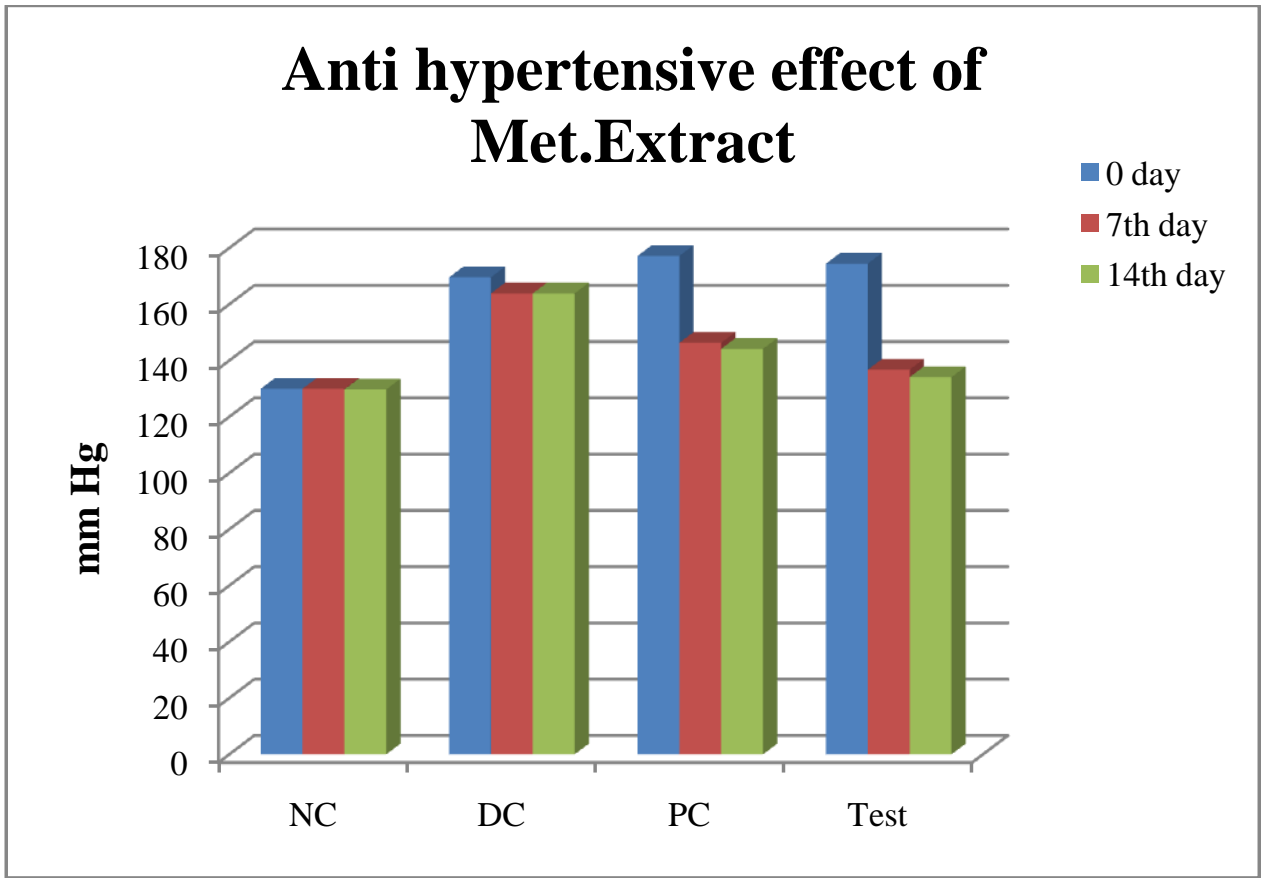

Fig 1: Antihypertensive effect of Methanolic extract on DOCA salt induced hypertensive rats NC-Normal Control; DC-Disease Control; PC-Positive control; Test

\section{REFERENCE}

[1]. Sakat, S S, S S Wankhede, A R Juvekar, V R Mali, and S L Bodhanka. "Antihypertensive effect of aqueous extract of Elaeocarpus ganitrus Roxb. seeds in renal artery occluded hypertensive rats." Int. J. PharmTech. Res. 1, no. 3 (2009): 779-782.

[2]. Ofem, O E, A E Eno, J Imoru, E N Kanu, F Unoh, and J O Ilou. "Effect of crude aqueous leaf extract of Visum album (mile stone) on hypertensive rats." Indian Journal of Pharmacology 39, no. 1 (2007): 15-19.

[3]. $\quad$ Oparil, S. "Treating multiple risk hypertensive populations." American Journal of Hypertension 12 (1999): 121129.

[4]. Bhatt, J D, U D Panchakshari, K G Hemavathi, and O D Gulati. "Effect of Abana, An ayurvedic preparation on ethinyl stradiol induced hypertension in rats." Indian Journal of Pharmacology 1, no. 30 (1998): 399-403.

[5]. W, H O. "Classification of hypertension." Report of WHO scientific group, Technical report series.

[6]. $\quad$ Fry, J. "Deaths and complications from hypertension." Journal of the Royal College of General Practitioners 25 (1975): 489-494.

[7]. Meredith, P A. "Candesartan Cilexetil- A review of effects on cardiovascular complications in hypertension and chronic heart failure." Current Medical Research and Opinion 23, no. 7 (2007): 1693-1705.

[8]. Ojewole, J A, and O O Odebiyi. "Neuromuscular and cardiovascular actions of tetramethylpyrazine from the stem of Jatropha podagrica." Planta Medica 38, no. 4 (1980): 332-338.

[9]. Kwan, C Y. "Plant derived drugs acting on cellular $\mathrm{Ca} 2+$ mobilization in vascular smooth muscle: Tetramethylpyrazine and tetrandrine." Stem Cells 12, no. 1 (1994): 64-67.

[10]. Nie, S Q, Z L Xie, and K C Lin. "Effects of tetrapyrazine on membrane fluidity and electrophoretic mobility of platelets and the relation to its antiaggregation effect." Acta Pharmaceutica Sinica 20, no. 9 (1985): 689-692.

[11]. King, V F, M L Garcia, and D Himmel. "Interaction of tetrandrine with slowly inactivating calcium channel modulation by an alkaloid of chinese medicinal herb origin." The Journal of Biological Chemistry 263, no. 5 (1988): 2238-2244.

[12]. Wang, Y L, and Y K Ba. "Pharmacological and electrophysiological actions of ligustrazine on cardiovascular tissues. A new Ca-channel blocker?" The Chinese Journal of Integrated Traditional and Western Medicne 5 (1985): 291-294.

[13]. O'Kane, P D, L R Queen, and Y Ji. "Aspirin modifies nitric oxide synthase activity in platelets: Effects of acute versus chronic aspirin treatment." Cardiovascular Research 59, no. 1 (2003): 152-159.

[14]. Wu, C-C, and M-H Yen. "Higher level of plasma nitric oxide in spontaneously hypertensive rats." The American Journal of Hypertension 12, no. 5 (1999): 476-482.

[15]. Umans, J G, and R Levi. "Nitric oxide in the regulation of blood flow and arterial pressure." Annual Review of Physiology 57 (1995): 771-790.

[16]. Ojewole, J A, D R Kamadyaapa, M M Gondwe, K Moodley, and C T Musabayane. "Cardiovascular effects of Persea americana Mill (Lauraceae) (avocado) aqueous leaf extract in experimental animals." Cardiovascular Journal of South Africa 18, no. 2 (2007): 69-76. 
[17]. Amira, O C, and N V Okubadejo. "Frequency of complementary and alternative medicine utilization in hypertensive patients attending an urban tertiary care in Nigeria." BMC Complementary and Alternative Medicine 7 (2007).

[18]. Shukla, S, R Patel, and R Kukkar. "Study of phytocehmcial and diuretic potential of methanol and aqueous extracts of aerial parts of Phyla nodiflora Linn." International Journal of Pharmacy and Pharmaceutical Science 1, no. 1 (2009).

[19]. Iwalokun, A B, A S Hodonu, S Nwoke, O Ojo, and P U Agomo. "Evaluation of the possible mechanisms of antihypertensive activity of Laranthus micranthus. An african misletoe." Biochemistry Research International Volume, 2011.

[20]. Ogawa, T, et al. "Evidence for load dependent and load independent determinants of cardiac natriuretic peptide production." Circulation 93 (1996): 2059-2067.

[21]. Mishra, Gaurav J, M N Reddy, and J S Rana. "Isolation of Flavonoid constituent from Launaea procumbens Roxb. by preparative HPTLC method." International Organization of Scientific Research Journal of Pharmacy 2, no. 4 (2012): 05-11.

[22]. Krege, J H, J B Hodgin, J R Hagaman, and O Smithies. "A noninvasive computerized tail cuff system for measuring blood pressure in mice." Hypertension 25 (1995): 1111-1115.

[23]. Prahalathan, P, S Kumar, and B Raja. "Effect of morin: A flavonoid against DOCA-Salt hypertensive rats. A dose dependent study." Asian Pacific Journal of Tropical Biomedicine, 2012: 1-6.

[24]. Mohring, J, B Mohring, J Naumann H, A Philippi, E Homsy, and H Orth. "Salt and water balance and renin activity in renal hypertension of rats." Am. J. Physiol. 228 (1975): 1847-1855.

[25]. Tomaschitz, A, S Pilz, E Ritz, B Pietsch, and R Pieber T. "Aldosterone and arterial hypertension." Nat. Rev. Endocrinol. 6 (2010): 83-93.

[26]. Iwashima, F, T Yoshimoto, I Minami, M Sakurada, Y Hirono, and Y Hirata. "Aldosterone induces superoxide generation via $\mathrm{NaCl}$ activation in endothelial cells." Endocrinology 149 (2008): 1009-1014.

[27]. Veeramani, C, B Aristatile, G Pushpavalli, and V Pugalendi K. "Effects of melothria maderaspatana leaf estract or antioxidant status in sham-operated and uninephrectomized DOCA-Salt hypertensive rats." Saud. J. Biol. Sci. 18 (2011): 99-105. 